\title{
A simple access to Vicinal Tricarbonyl Compounds from Morita-Baylis-Hillman adducts
}

\author{
Marilia Simão Santos and Fernando Coelho* \\ DQO - Chemistry Institute - UNICAMP - PO box 6154 - 13084-970 - Campinas, SP - Brazil \\ *coelho@iqm.unicamp.br
}

Keywords: $M B H$ adducts, ozonolysis, vicinal tricarbonyl compounds

\section{INTRODUCTION}

Vicinal tricarbonyl compounds are important synthetic building blocks and have attracted the attention of many organic chemists due to the presence of highly active central carbonyl group. ${ }^{1}$

These compounds are useful precursors to elaborate heterocyclic compound and biologically important substances. ${ }^{1,2,3}$ (Figure 1).

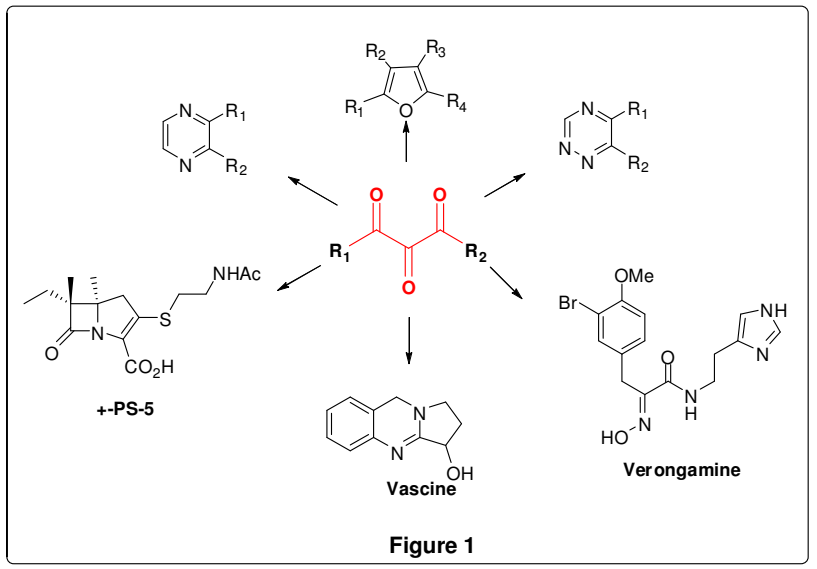

\section{RESULTS AND DISCUSSION}

The study began with a synthesis of $\mathrm{MBH}$ adducts using a protocol developed by our research group. ${ }^{4}$ After that $\mathrm{MBH}$ adducts were oxidized with 2iodoxibenzoic acid (IBX) in acetonitrile providing 1,3dicarbonyl compounds in excellent yields (Table 1). The derivatives were placed under ozonolysis conditions, using methanol as solvent at $-78^{\circ} \mathrm{C}$ (Scheme 1).

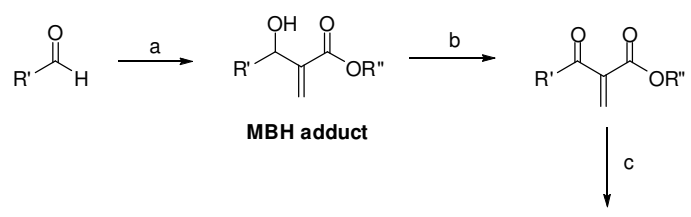

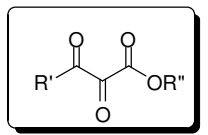

Reagents and Conditions: a) DABCO, Methyl acrilate, ta; b) IBX, $\mathrm{CH}_{3} \mathrm{CN}, 70^{\circ} \mathrm{C}$; b) i. $\mathrm{O}_{3}, \mathrm{MeOH}$ or $\mathrm{CH}_{2} \mathrm{Cl}_{2},-78{ }^{\circ} \mathrm{C}$; ii. $\left(\mathrm{CH}_{3}\right)_{2} \mathrm{~S}$

Scheme 1
Table 1: Yields for each stage of our approach

\begin{tabular}{|c|c|c|c|c|c|}
\hline \multirow{2}{*}{ Entry } & \multirow{2}{*}{$\mathbf{R}^{\prime}$} & \multirow{2}{*}{$\mathbf{R}^{\prime \prime}$} & \multicolumn{3}{|c|}{ Yield (\%) } \\
\hline & & & $a^{a}$ & b & $c^{\mathrm{a}}$ \\
\hline 1 & & Me & 98 & 72 & 20 \\
\hline 2 & & $\mathrm{Me}$ & 83 & 90 & 57 \\
\hline 3 & & $\mathrm{Me}$ & 66 & 98 & 76 \\
\hline 4 & & $\mathrm{Me}$ & 70 & 94 & 20 \\
\hline 5 & & $\mathrm{Me}$ & 71 & 100 & 10 \\
\hline
\end{tabular}

\section{CONCLUSION}

Vicinal tricarbonyl compounds are important and versatile intermediate of widespread application in organic synthesis. The described methodology is simple and allows the access to vicinal tricarbonyl compounds in three steps with an overall yield range from 7 to $49 \%$. This approach is a gentler and fast alternative compared to existing methods allowing the preparation of this structural pattern.

\section{ACKNOWLEDGEMENTS}

We thank Fapesp and CNPq for financial support

\section{REFERENCES}

${ }^{1}$ Wasserman, H.H.; Parr, J. Acc. Chem. Res, 2004, 37, 687

${ }^{2}$ Nair, V.; Deepthi, A. Tetrahedron Letters, 2006, 47, 2037

${ }^{3}$ Adlington, R.M.; Baldwin, J.E.; Catterick, D.; Pritchard, G.J. J. Chem. Soc.; Perkin Trans. 1, 2001, 668

${ }^{4}$ Coelho, F.; Almeida, W. P.; Veronese, D.; Lopes, E. C. S..; Silveira, G. P. C.; Rossi, R. C. Tetrahedron, 2002, 58, 7437. 